\title{
Equity in utilization of health care services in Turkey: an index based analysis
}

Selcen Öztürk ${ }^{1}$ and Dilek Başar ${ }^{1}$

${ }^{1}$ Department of Economics, Hacettepe University Beytepe Campus, Ankara, Turkey (Correspondence to: Selcen Öztürk: selcen@hacettepe.edu.tr).

\begin{abstract}
Background: Equity in the use of health care services is an issue which has increasingly been on the health policy agenda over recent years in both middle- and low-income countries.
\end{abstract}

Aims: The purpose of this study was to investigate the degree and progress of equity in health care utilization in Turkey during 2008-2012.

Methods: Wed use data from health surveys $(2008,2010,2012)$ conducted by the Turkish Statistical Institute. The concentration index (CI) and the horizontal equity index (HI) were calculated as a measure of equity, and a Blinder-Oaxaca decomposition analysis was applied.

Results: The general practitioner (GP), specialist and inpatient visits display a pro-poor orientation. Averages of the CI and $\mathrm{HI}$ indices for 2008-2012 were 0.74 and -0.17 for GP visits, 0.75 and -0.13 for specialist visits, 0.83 and -0.31 for inpatient visits.

Conclusion: Our findings indicate that health care utilization in Turkey appears to have become equitable over the years; however, the sustainability of equity is an issue of concern.

Keywords: Horizontal equity, utilization of health care services, concentration index, horizontal equity index, Oaxaca decomposition

Citation: Öztürk S; Başar D. Equity in utilization of health care services in Turkey: an index based analysis. East Mediterr Health J. 2020;26(5):547-555 https://doi.org/10.26719/emhj.19.090

Received: 02/01/18; accepted: 02/09/18

Copyright (C) World Health Organization (WHO) 2020. Opens Access. Some rights reserved. This work is available under the CC BY-NC-SA 3.0 IGO license (https://creativecommons.org/licenses/by-nc-sa/3.o/igo).

\section{Introduction}

Equity in the use of health care services is an issue, which has increasingly been on the health policy agenda in recent years in both middle- and low-income countries. (1). Equity and equality are different terms, which should be described with caution. Equity, with its moral and ethical features, differs from equality, which indicates a simple mathematical condition, meaning 2 things being equivalent. Therefore, inequality in health care utilization is related to unequal utilization, which is due to characteristics such as age, sex and socioeconomic status (2). In this regard, equity can be defined as everyone in equal need of treatment using similar treatment regardless of any economic or other conditions (3). In other words, differences relating to the utilization of health care services between the advantaged and disadvantaged segments of a population should be eliminated in order to provide equity (4).

Equity is evaluated through 2 main aspects. "Vertical equity" requires payments should be related to ability to pay (5), whereas "horizontal equity" relates to the opportunity of utilizing equal treatments for equal needs regardless of socioeconomic status (3). In other words, equity can be said to exist in cases where need is the primary cause of the utilization of health care services $(6,7)$. Therefore, equity is evident when, for example, enabling factors such as income and health insurance do not play a significant role in determining the beneficiaries of health care services (8). In this respect, a number of existing studies for Turkey have investigated vertical equity $(9-11)$. In consequence, our study focuses on the concept of horizontal equity in the Turkish health care system. Specifically, the aim of this paper is to examine equity in the use of health care services in Turkey by using the 2008, 2010 and 2012 health surveys implemented by the Turkish Statistical Institute (TurkStat).

As a first step, we calculated and graphed the concentration index (CI) as described by O'Donnell et al. (1). The need-standardized horizontal inequity (HI) index proposed by Wagstaff and Van Doorslaer (3) was also calculated. The HI index has been increasingly used in equity studies over recent decades, especially for the developed countries (5,12-14). However, it is clear that low- and middle-income countries are at more risk of suffering from inequity in the utilization of health care services compared with high-income countries. Therefore, some studies turn their attention to experiences of incurring inequity in the health care system in low- and middle-income countries (15-18). The Oaxaca-Blinder type decomposition is used to further investigate the differences between income groups following the methodology suggested by O'Donnell et al. (1)

In the case of Turkey, most studies have focused on analysing the determinants for utilization of different types of health care $(19,20)$. To our best knowledge, there is only one study focusing on inequity in the utilization of health care services for 2008 (21). The researchers 
found evidence on pro-rich inequity in specialist and dental care and pro-poor distribution for emergency care, inpatient care and general practitioner (GP) visits. Although this study is important in terms of offering a starting point for the evaluation of inequity of utilization of health care services in Turkey, it has the limitation of not providing the improvement of equity (or inequity) over time. However, it is important to examine the progress of equity in Turkey, which is a particular policy area given the ongoing health reforms since 2003 through the Health Transformation Programme (HTP). The HTP has been focusing on 3 main policy areas: the financing, organization and delivery of health care services (22). In the General Health Insurance System, health care financing depends largely on premiums which are directly or indirectly collected from people utilizing health care services. Furthermore, the purchaser and provider functions of the Ministry of Health hospitals were separate. After 2003, Turkey extended the scope of financial protection against high levels of health care expenditures by expanding the health insurance coverage to improve equity in the utilization of health care services. The years 2010 and 2012 are especially important in the restructuring of the Turkish health care system as a person list-based family medicine model was completely implemented in 2010 and the public hospitals were unified under a single umbrella in 2012. Other than these 2 important health policies, many reforms relating to, for example, co-payments, hospital structure and extra payments for private hospitals have been implemented since 2003, which may have considerable effects on the utilization of health care services in Turkey. Our study extends the existing research by calculating both the CI and HI using the 2008, 2010 and 2012 health surveys and, thus, offers a set of policy implications for a long policy period in Turkey.

\section{Methods}

TurkStat, as a nationally representative survey, administers the Turkish Health Survey biennially. The most recent available survey is for 2012 for equity analysis. Even though the 2014 and 2016 surveys are available, they lack crucial questions to evaluate equity in health utilization.

TurkStat used strata and 2-phase cluster sampling methods as sampling methodologies for the surveys. For external stratification, rural-urban difference was used (settlements with a population 20000 and under are regarded as rural; settlements with a population of 20001+ are regarded as urban). The first stage-sampling unit is the blocks selected from clusters, containing an average of 100 households, and the second stage-sampling unit is the households selected systematically from each cluster.

In 2008, among urban areas 5580 households were selected within 372 clusters containing 15 households in each block. In 4294 of these households, questionnaires were completed. In rural areas, 2330 households were selected from 233 clusters containing 10 households in each cluster. In 1846 of these households questionnaires were completed.
In 2010, among urban settlements, 5696 households were selected from 356 clusters containing 15 households in each cluster. In 4682 of these households, questionnaires were completed. In rural settlements, 2190 households were selected from 219 clusters containing 10 households in each cluster. Questionnaires were completed in 1869 of these households.

In 2012, among urban settlements, 10656 households were selected from 888 blocks containing 12 households in each cluster. In 8928 of these households, questionnaires were completed. In rural settlements; 3744 households were selected from 468 blocks containing 8 households in each cluster. In 3232 of these households, questionnaires were completed.

Weighting procedures were carried out by TurkStat to obtain parameters from the dataset resulting from sampling. The sampling frame of the surveys was the National Address Database, which constitutes a base for an "address based registry system", which was completed in 2007 and updated in February 2012. Settlements with population less than 132 were not included in the frame because it was considered that an adequate number of sample households might not be reached. All residential areas located within the coverage of Turkey were included in the sample selection and all members who had received health services in the previous year were covered. Survey questions are available for the 0-6 and 7-14 years age groups, however, our study includes only those aged $15^{+}$years. In total, 20624 individual interviews were completed for 2008, 20200 for 2010 and 37979 for 2012. The surveys were administered to different individuals each year and hence are not in panel data format.

As a first step of analysing equity, this study employs the concentration index (CI), employed for its computational simplicity and the concentration curves (CC) are drawn for easy visualization and for comparison purposes. However, it should be noted that the CC and $\mathrm{CI}$ are used to capture socioeconomic inequalities rather than inequities (1). Therefore, only HI index results are interpreted.

CI is calculated following O'Donnell et al. (1):

$$
C I=\frac{2}{N \mu} \sum_{i}^{n}=1 h_{i} r_{i}-1 \frac{-1}{N}
$$

Where, $h_{i}$ denotes the health variable, in this case health service utilization, and $\mu$ represents its mean; $r_{i}$ represents rank of the individual with $\mathrm{I}=1$ for poorest and $\mathrm{I}=\mathrm{N}$ for the richest, where $\mathrm{N}$ is the total number of living standards groups. Alternatively, the CI can be defined using the concentration curve. The $\mathrm{CI}$ is calculated as twice the area between the concentration curve and the line of equality. The index takes the value of zero if there is no inequality between income groups. The CI takes values between -1 and 1 . When the concentration curve lies above the line of equality, the CI takes a negative value and this indicates pro-rich inequalities in the health variable of interest (1). 
The HI index proposed by Wagstaff and Van Doorslaer (3) is calculated in 3 basic steps. As a first step, the utilization variable $\left(\mathrm{y}_{\mathrm{i}}\right)$ is used as a dependent variable and regressed against "need" and "non-need" variables.

$$
y_{i}=a+\sum_{k} y_{k} x_{k}+\sum_{p} \delta_{p} z_{p}+\epsilon_{i}
$$

Where, $y_{i}$ is the use of health care services by the $i_{t h}$ individual. In this study the choice for dependent variables are: GP visits, specialist visits and inpatient visits. Since these dependent variables are all in binary form, probit regression is employed rather than linear regression. In equation [2], $\mathrm{X}_{\mathrm{k}}$ is a vector of need determining variables and $Z_{p}$ is a vector of non-need variables. $\alpha, \delta_{k}, \delta_{p}, \gamma_{k}$ and $\gamma_{p}$ are parameters and $\varepsilon$ is the error term. The need variables include the following factors; sex, age, self-assessed health status, physical illnesses and chronic illnesses or any kind of discomfort reported by the individual which will cause the individual to utilize health services. Nonneed variables, on the other hand, include factors other than need variables but which still have an impact on utilization; marital status, education, employment, residence and health insurance.

Equation [2] is used to generate the $i_{\text {th }}$ individual's "predicted" demand on the basis of need. The predicted demand, $y_{i}^{x}$, generated using equation [2] is shown in equation [3]. The need and non-need variables are represented as $\check{\mathrm{X}}_{k}$ and $\check{Z}_{p}$ in equation [3] in order to differentiate from equation [2].

The second stage is to standardize the predicted yi values according to need variables (X). Nonneed variables $(Z)$ are also used as control variables. $\widehat{y}_{i}=\hat{a}+\hat{\beta} \operatorname{In}\left(\widetilde{\ln c}_{i}\right)+\sum_{k} \hat{y}_{k} \check{X}_{k}+\sum_{p} \hat{\delta}_{p} \check{Z}_{p}$

Then, standardized demand for a particular health service is calculated as follows:

$$
\hat{y}_{i}{ }_{i}=y_{i}-\hat{y}^{x_{i}+\bar{y}}
$$

$\mathrm{W}$ h e r e $\hat{y}^{\mathrm{S}}$ i represents the standardized predicted demand, represents the actual demand, represents the predicted demand and represents the mean value. Finally, the $\mathrm{HI}$ index is calculated as the third stage:

$$
H I=2 \int_{0}^{1}\left[L_{p}(p)-L_{m}(p)\right] d_{p}
$$

Where, $L_{p}(p)$ is the $L_{m}(p)$ concentration curve for the predicted demand and is the concentration curve for the actual demand, shown in Figures 1-3 for visualization of the data. Twice the integral of the area between the 2 curves yields the standardized $\mathrm{HI}$ index. The HI index ranges from -2 to 2 . A positive $\mathrm{HI}$ index value is interpreted as the existence of inequities favouring rich over poor (pro-rich) and a negative value is interpreted as the existence of pro-poor inequities (3).
Finally, this study employs a Blinder-Oaxaca type decomposition of the HI index. The Oaxaca decomposition is utilized in order to assess and analyse the main components of inequities. The decomposition explains the differences among the means of the selected outcome variables between 2 groups (1). The outcome variables in this study are GP visits, inpatient visits and specialist visits and the decomposition reveals the differences in the means of the calculated HI index among poor and non-poor groups.

\section{Results}

The data indicate that utilization of health care services increased considerably from 2008 to 2012 for both GP and specialist visits (Table 1). However, the inpatient visits were steady throughout the years under consideration. The increased use of health care for GP and specialist visits brings out the important question of equity. The representation of males and females was almost equal across all survey years. In 2008 almost $70 \%$ of those surveyed lived in an urban area and in 2012 this had increased to around $73 \%$. The proportion of individuals with health insurance was over $85 \%$ for 2008 and had increased to $89.78 \%$ in 2012; this can be regarded as a reflection of the General Health Insurance scheme implemented in Turkey since 2008. Almost 38\% of the individuals stated that they had a health problem that lasted more than 6 months and this did not improve substantially over the period of the study, indicating that there are individuals in "need" of medical treatment.

The proportion of individuals who felt the need to use health services but were unable to do so severely diminished over the years for all types of health care (Table 2). Furthermore, in 2008 almost $40 \%$ of the individuals in the lowest income group had felt a need to use specialist services in the previous year but could not. This decreased to just over $15 \%$ in 2012 . There is also a declining trend for individuals in the poor income group. However, for the middle income, rich and very rich groups, the ratio increased over time. For inpatient care, the proportion of individuals who felt the need to use health services but were not able to decreased for the 2 lowest and for the highest income groups. It can be argued that there was an improvement in equity over time since opportunities changed in favour of those in the lower income groups.

Calculating $\mathrm{CI}$ and $\mathrm{HI}$, this study employed utilization of health care services as the health variable. The outcome variables were GP, specialist and inpatient visits, all of which are binary. Figures 1 to 3 show the concentration curves for classical and standardized demands for GP, specialist and inpatient visits. The results indicate that health service utilization is pro-poor oriented and that it improved over the years. (Detailed estimation results are available on request.)

Figure 4 presents the results of the Oaxaca decomposition (23). Our results indicate that the importance of non-need factors is increasing over time (detailed estimation results are available on request). 
Figure 1 Concentration curves for classical and standardized demands for general practitioner (GP) visits, Turkey, 2008-2012 (HI = horizontal equity index)
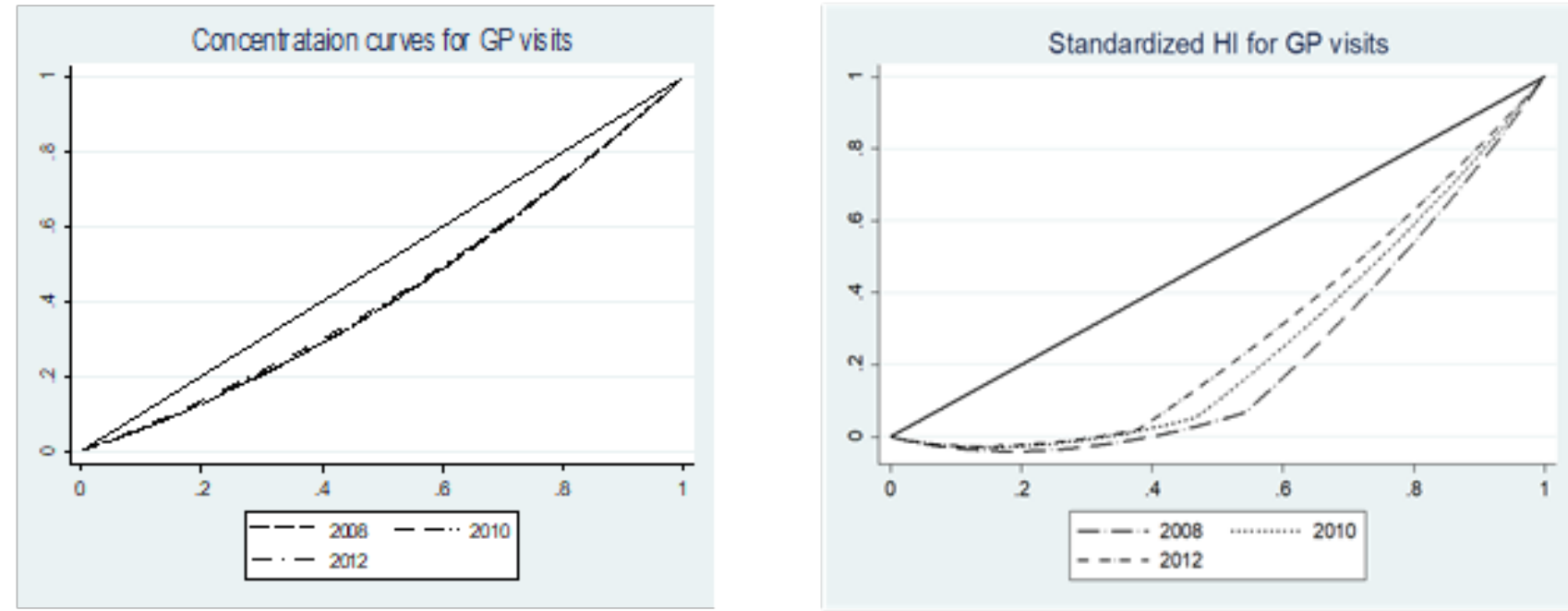

Figure 2 Concentration curves for classical and standardized demands for specialist visits, Turkey, 2008-2012 (HI = horizontal equity index)
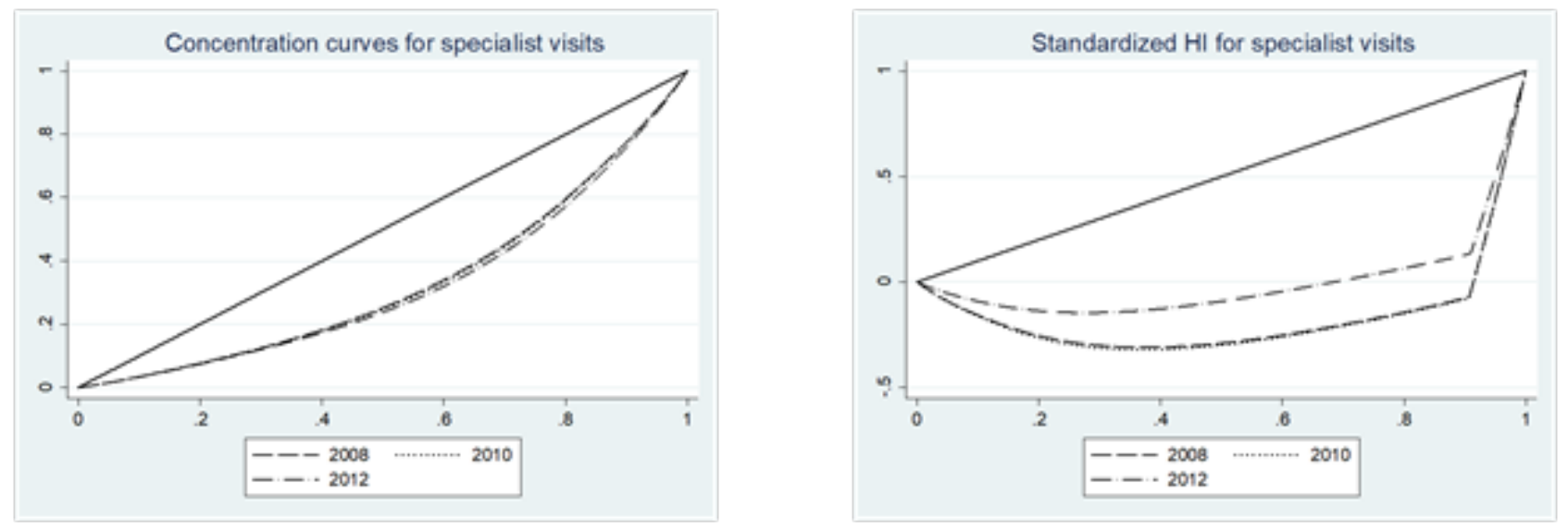

Figure 3 Concentration curves for classical and standardized demands for inpatient visits, Turkey, 2008-2012 (HI = horizontal equity index)
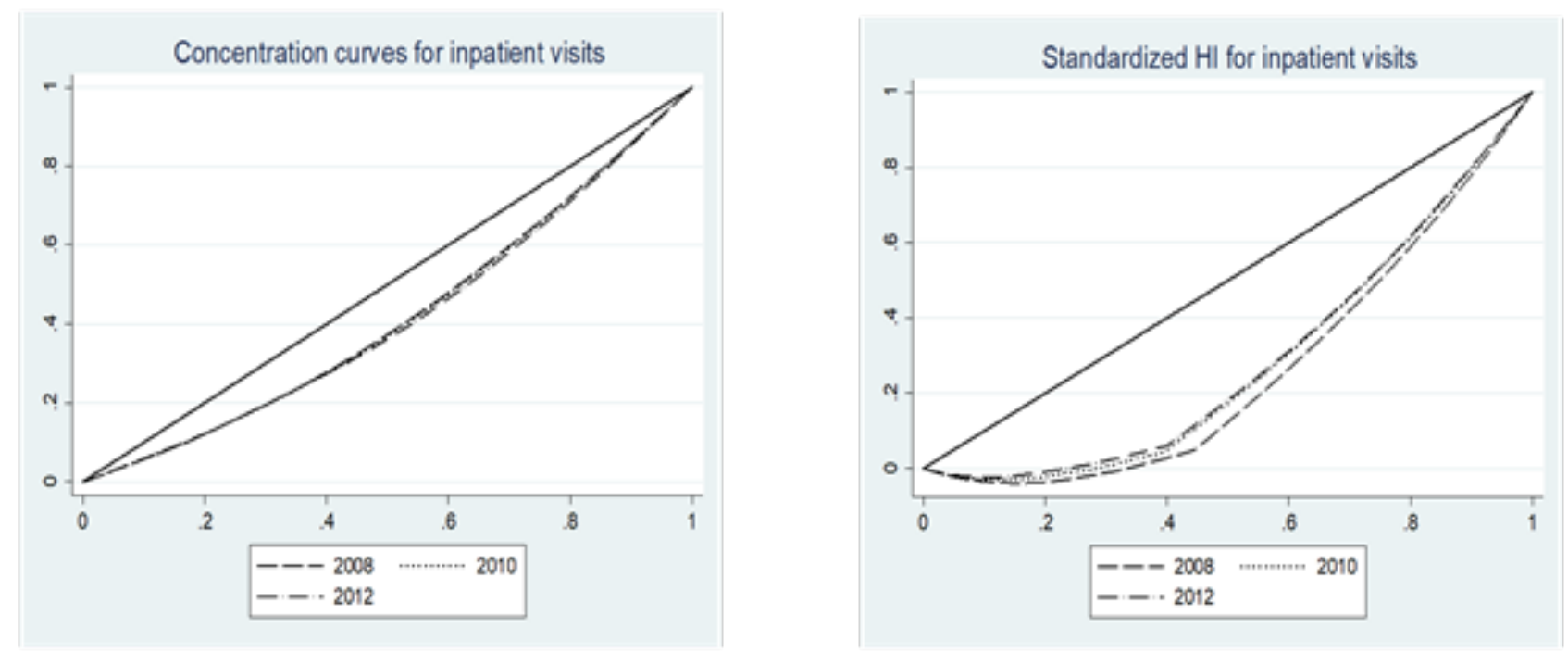


\begin{tabular}{|c|c|c|c|}
\hline \multirow[t]{2}{*}{ Characteristic } & \multicolumn{3}{|c|}{ Year } \\
\hline & $\begin{array}{c}2008(\%) \\
(n=14655)\end{array}$ & $\begin{array}{c}2010(\%) \\
(n=14447)\end{array}$ & $\begin{array}{c}2012(\%) \\
(n=28055)\end{array}$ \\
\hline Female & 54.54 & 56.48 & 53.93 \\
\hline \multicolumn{4}{|l|}{ Age group (years) } \\
\hline $15-24$ & 19.64 & 18.46 & 18.25 \\
\hline $25-34$ & 22.59 & 20.09 & 19.98 \\
\hline $35-44$ & 19.71 & 19.51 & 19.80 \\
\hline $45-54$ & 16.57 & 17.34 & 17.54 \\
\hline $55-64$ & 10.98 & 12.15 & 12.33 \\
\hline $65-74$ & 6.46 & 7.72 & 7.54 \\
\hline $75^{+}$ & 4.05 & 4.73 & 4.56 \\
\hline Urban residence & 68.87 & 71.13 & 73.63 \\
\hline Insured & 86.05 & 85.54 & 89.78 \\
\hline \multicolumn{4}{|l|}{ Education status } \\
\hline Illiterate & 12.60 & 11.41 & 10.37 \\
\hline Literate $^{\mathrm{a}}$ & 7.06 & 7.64 & 5.96 \\
\hline Primary school & 39.52 & 37.47 & 35.31 \\
\hline Secondary school & 15.33 & 17.41 & 18.75 \\
\hline High school & 16.77 & 15.78 & 17.60 \\
\hline University & 8.09 & 9.60 & 11.16 \\
\hline Graduate & 0.64 & 0.69 & 0.85 \\
\hline \multicolumn{4}{|l|}{ Marital status } \\
\hline Single & 22.27 & 21.89 & 22.82 \\
\hline Married & 70.13 & 69.43 & 68.51 \\
\hline Divorced-widowed & 7.60 & 8.68 & 8.67 \\
\hline Employment status: employed & 26.54 & 36.29 & 37.23 \\
\hline \multicolumn{4}{|l|}{ Income group $^{b}$} \\
\hline Very poor $(\leq \$ 271)$ & 27.47 & 17.60 & 8.85 \\
\hline Poor $(\$ 272-\$ 390)$ & 21.26 & 21.58 & 12.33 \\
\hline Middle income (\$391-\$546) & 20.91 & 20.73 & 24.51 \\
\hline $\operatorname{Rich}(\$ 547-\$ 800)$ & 16.94 & 19.73 & 22.21 \\
\hline Very rich $(\geq \$ 801)$ & 12.53 & 19.49 & 30.92 \\
\hline Non-respondent & 0.89 & 0.87 & 1.18 \\
\hline Health problems for more than 6 months & 37.59 & 37.52 & 36.11 \\
\hline Used GP services in previous 12 months & 45.89 & 53.30 & 62.22 \\
\hline $\begin{array}{l}\text { Used outpatient health care in previous } 12 \\
\text { months }\end{array}$ & 55.49 & 60.41 & 60.01 \\
\hline $\begin{array}{l}\text { Use of inpatient health care in previous } 12 \\
\text { months }\end{array}$ & 9.31 & 9.29 & 9.07 \\
\hline
\end{tabular}

andividuals who are literate but have no formal education certificate or diploma.

${ }^{b}$ Turkish liras converted to US\$ at the July 2018 rate of 4.65.

$G P=$ general practitioner

According to Oaxaca type decomposition, positive values are associated with pro-rich orientation, whereas negative values are associated with pro-poor orientation. Age/sex represent all age and sex combinations. Health is designed as a measure of health status and includes self-assessed health, physical functioning limitations and chronic conditions. In line with the calculations of the concentration index, age/sex factors and health status are treaded as need factors and residence, insurance, education, marital status, employment and income are treated as non-need factors. When the contribution of need factors is investigated, a clear pattern of pro-poor orientation emerges. For non-need factors, it is possible to argue an overall pro-rich orientation. 


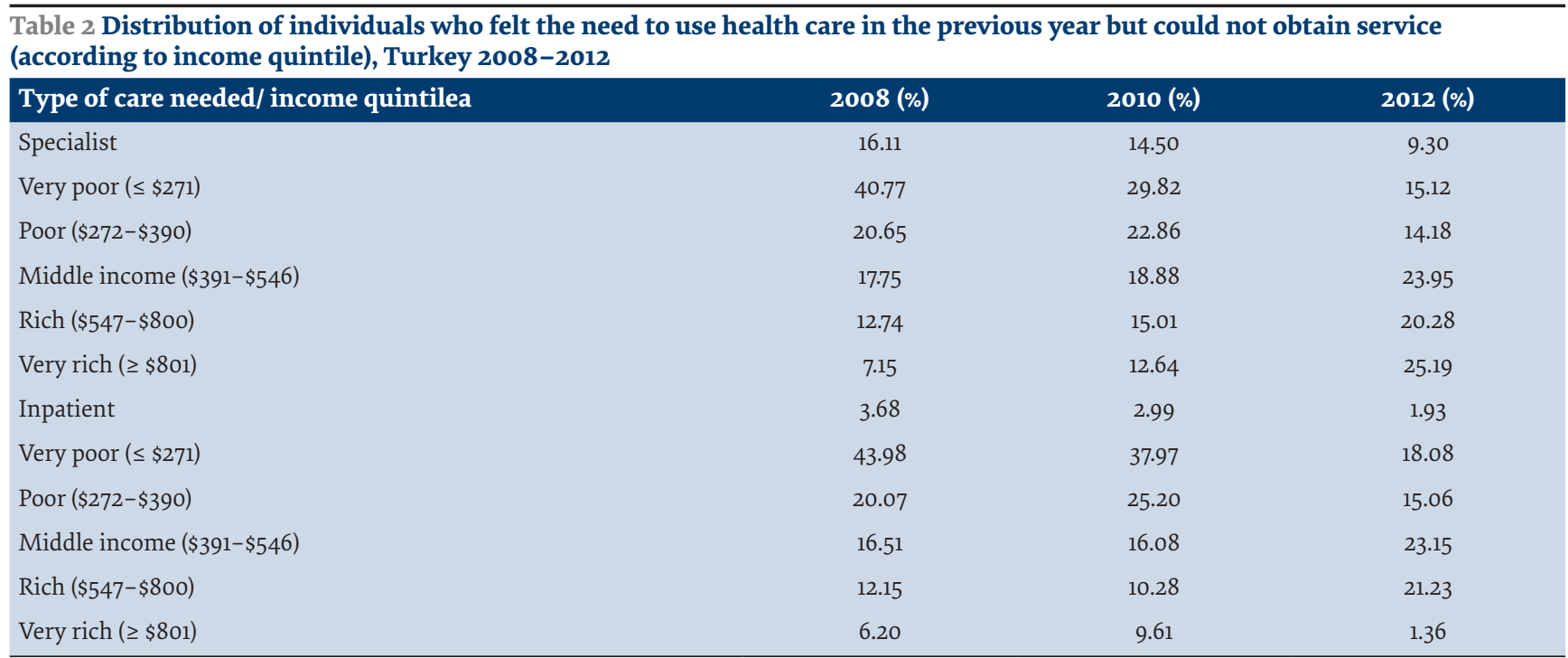

${ }^{a}$ Turkish liras converted to US\$ at the July 2018 rate of 4.65 .

\section{Discussion}

Turkey has been experiencing important changes to its health system resulting from health reforms that started at 2003. The Health Transformation Programme, which has been implemented in Turkey since 2003, is based on the joint report prepared by a commission of specialists from Turkey and the World Bank (24). It aims to intervene in the 3 basic fields of the health system: organization, finance and health service supply. With this programme, Turkey agreed to execute 2 important changes to the health system. First, to integrate 3 main security institutions under one umbrella institution. Second, to introduce GP services countrywide. The programme specifically aims to increase equity in access and utilization of health services. Therefore, via assessing the level and progress of equity in the utilization of health services in
Turkey, our study fills in an important gap in the existing literature. Furthermore, this study is important to show the effects of the specific policy changes which have occurred over time and also to determine accurate policy implications for the Turkish health system.

Prior to 2003, Turkey had 3 main governmentbased security institutions financing health services. Private security companies were also active. However, a significant part of the population was not covered by any type of social security. For example, in 2003, only $25 \%$ of the poorest population were insured. One of the main aims of HTP was to increase access to health care and, thus, increase the percentage of population who are insured. After 13 years in the programme, the percentage of insured in this group has increased to $95 \%$ (25). In line with the increase in social security coverage, utilization

Figure 4 Decomposition of the concentration index (Oaxaca decomposition), Turkey, 2008-2012

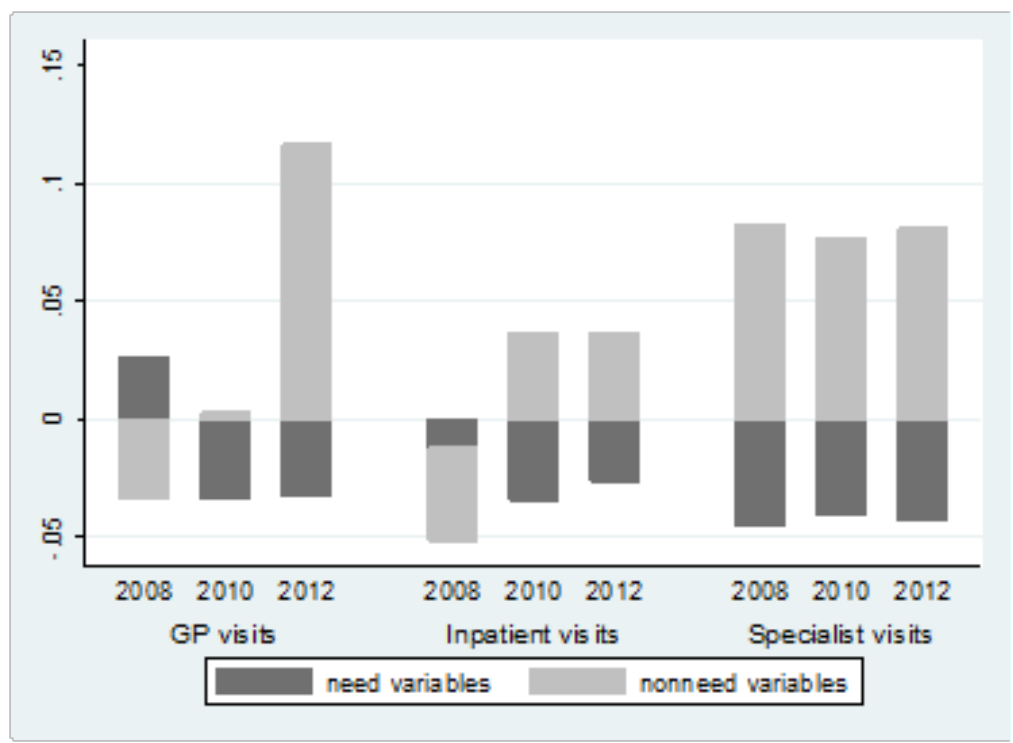


of health services has also increased, for example, the average number of physician consultations per year has increased $141 \%$ over the $2003-2012$ period (26).

The integration of 3 main security institutions under one umbrella institution was implemented in 2008. In October 2008, the finance system was unified and the General Health Insurance (GHI) system was suggested. The implementation of the GHI started in 2012. The second important step of the HTP, a person list-based family medicine model, has been implemented since 2010. And GP services have been free of charge since the beginning of the programme. However, GP services for Turkey are far from their counterpart services in other European countries. The main problem is an inadequate work force, high numbers of patients per GP and the lack of multidisciplinary implementation (27,28). In contrast to GP services, specialist care and inpatient care are subject to payment. The amount of out-of-pocket payments necessary for these services was at its lowest level at 2010 (29).

At the end of 2011, the government introduced a performance based supplementary payment system for physicians. This ensures that a supplementary payment has been made to the physicians according to their "contribution" to services. The contribution can be in the form of patients examined, operations, workups or any type of services that can be listed as a source of income to the hospital (29). Finally, extra payments that private hospitals can receive are bounded with law in Turkey. The amount of extra payments that private hospitals can charge has increased from 30\% to 90\% from 2008 to 2012. Since this study covers both public and private health facilities, such a dramatic increase is an important factor in considering the effects of the reforms on the utilization of health care services.

For the years under consideration in this study, health care utilization in Turkey appears to have become equitable. To be specific, GP and specialist visits display a pro-poor orientation and inpatient visits display the highest pro-poor orientation among all types of health care. When considering the change over time, it can be argued that for GP visits and inpatient visits the inequities are improving while for specialist visits they stay the same over time. Due to the person listbased family medicine model, which is an important component of the HTP, free of charge and countrywide GP coverage increases the number of GP visits for individuals in the most disadvantaged segments of the population. Therefore, improving pro-poor inequities in $\mathrm{GP}$ visits can be attributed to the implementation of the GP care system in HTP.

There is a stable pro-poor orientation for all years for specialist visits. Evan though after 2010 necessary outof-pocket payments for both public and private health facilities increased, the indices still favour the poor. The highest levels of pro-poor inequity are also observed in inpatient visits. Furthermore, there is an increasing trend in pro-poor inequities in inpatient visits. This can mainly be attributed to the fact that individuals belonging to the high-income group choose private facilities for inpatient visits. With the rapid increases in necessary out-ofpocket payments for private health services, it is expected to observe inequities favouring the poor.

Overall, government policies aimed at increasing access have led to a fairer health care utilization pattern over time in Turkey as indices for all types of health care suggest pro-poor orientation.

Funding: This study is part of a research project funded by TUBITAK (project ID: 114K958). Authors thank TUBITAK for this financial support.

Competing interests: None declared.

\section{Équité dans l'utilisation des services de soins de santé en Turquie : analyse basée sur des indices \\ Résumé}

Contexte : Ces dernières années, l'équité dans l'utilisation des services de soins de santé est une question de plus en plus présente dans les programmes concernant les politiques de santé, à la fois dans les pays à revenu faible et intermédiaire.

Objectifs : La présente étude visait à examiner le degré d'équité et sa progression dans le recours aux services de soins de santé en Turquie pour la période comprise entre 2008 et 2012.

Méthodes : Nous avons utilisé les données d'enquêtes de santé (2008, 2010, 2012) menées par l'Institut statistique de Turquie. L'indice de concentration (IC) et l'indice d'équité horizontale (EH) ont été calculés pour mesurer l'équité, et l'analyse de décomposition de Blinder-Oaxaca a été appliquée.

Résultats : Les chiffres relatifs aux visites rendues à un médecin généraliste, un spécialiste et aux patients hospitalisés démontrent une orientation centrée sur les pauvres. Les indices IC et EH moyens pour la période de l'étude étaient de 0,74 et $-0,17$ pour les visites chez le médecin généraliste, de 0,75 et -0,13 pour les visites chez un spécialiste, et de 0,83 et $-0,31$ pour les visites rendues aux patients hospitalisés.

Conclusion : Nos résultats indiquent que le recours aux soins de santé en Turquie semble être devenue équitable au fil des ans. Toutefois, la pérennité de l'équité demeure un sujet de préoccupation. 


$$
\text { الخلإسين أوزتورك، ديليك بصر الاستفادة من خدمات الرعاية الصحية في تركيا: تحليل قائم على المؤشرات }
$$

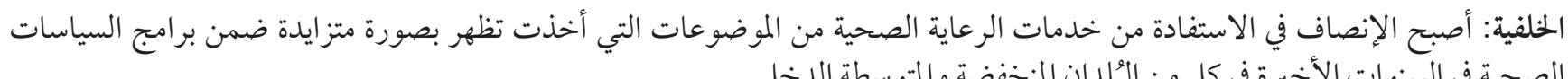

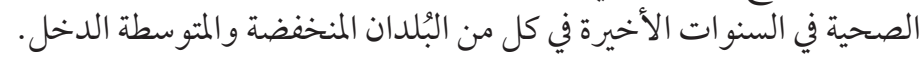

الأهداف: هدفت هذه الدراسة إلى تحري مستوى الإنصاف في الاستفادة من خدمات الرعاية الصحية في تركيا والتقدم المحرز في هذا الصدد خلال الفترة من 2008 و 2012 - 2012.

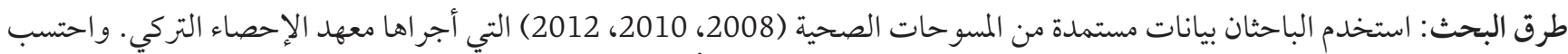

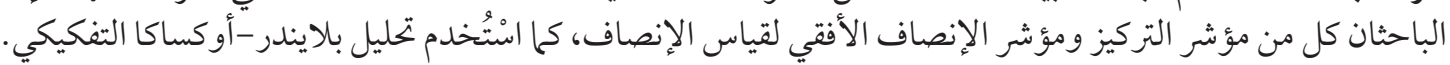

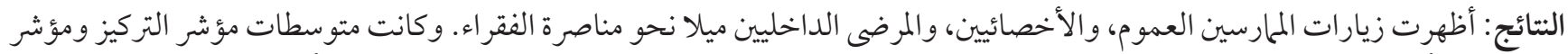

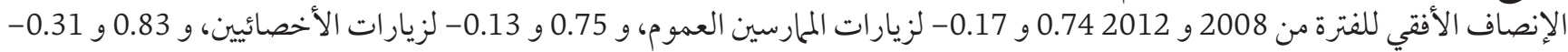
لزيارات المرضى الداخليين.

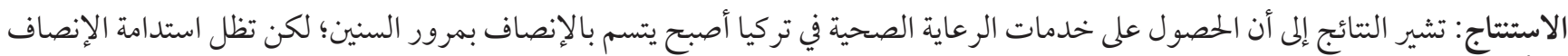
مسألة باعثة على القلق.

\section{References}

1. O'Donnell O, van Doorslaer E, Wagstaff A, Lindelow M. Analyzing health equity using household survey data, a guide to techniques and their implementation, 1st ed. Washington DC: World Bank; 2008.

2. Collins Dictionary. Glasgow: HarperCollins; 2011.

3. Wagstaff A, van Doorslaer E. Equity in health care finance and delivery. In: Culyer A, Newhouse J, eds. North Holland handbook in health economics. Amsterdam: Elsevier; 2000.

4. Braveman P, Gruskin S. Defining equity in health. J Epidemiol Community Health. 2003 Apr;57(4):254-8. doi:10.1136/jech.57.4.254

5. van Doorslaer E, Wagstaff A, van der Burg H, Christiansen T, De Graeve D, Duchesne I, et al. Equity in the delivery of health care in Europe and the US. J Health Econ. 2000 Sep;19(5):553-83. PMID:11184794

6. Andersen, R. Revisiting the behavioral model and access to medical care: does it matter? J Health Soc Behav. 1995 Mar;36(1):1-10. PMID:7738325

7. Aday LA, Begley CE, Lairson DR, Balkrishman R. Evaluating the healthcare system, effectiveness, efficiency and equity. Chicago, Health Administration Press; 2004.

8. Andersen RM, Davidson PL. Improving access to care in america, individual and contextual indicators in changing the U.S. health care system. In: Andersen RM, Rice TH, Kominski GF, eds. Key issues in health services policy and management. San Francisco: John Wiley \& Sons, Inc; 2007.

9. Erus B, Aktakke N. Impact of healthcare reforms on out-of-pocket health expenditures in Turkey for public insurees. Eur J Health Econ. 2012 Jun;13(3):337-46. doi:10.1007/s10198-011-0306-2

10. Yardim MS, Cilingiroglu N, Yardim N. Financial protection in health in Turkey, the effects of the Health Transformation Programme. Health Policy Plan. 2014 Mar;29(2):177-92. doi:10.1093/heapol/cztoo2

11. Brown S, Hole AR, Kilic D. Out-of-pocket health care expenditure in Turkey: analysis of the 2003-2008 household budget surveys. Economic Modelling. 2014;41:11-8. https://doi.org/10.1016/j.econmod.2014.05.01

12. Morris S, Sutton M, Gravelle H. Inequity and inequality in the use of health care in England: an empirical investigation. Soc Sci Med. 2005 Mar;60(6):1251-66. doi:10.1016/j.socscimed.2004.07.016

13. Masseria C, Giannoni M. Equity in access to health care in Italy, a disease-based approach. Euro J Public Health. Oct;20(5):504-10. doi:10.1093/eurpub/ckq029

14. McLeod L. Income-related horizontal inequities in physician use by asthmatics and diabetics, evidence using linked administrative data from Ontario. Hamilton: McMaster University, Research Data Centre; 2011 (Research Paper, 201122 ).

15. Phiri J. Ataguba JE. Inequalities in public healthcare delivery in Zambia. Int J Equity Health. 2014 Mar 19;13:24. doi:10.1186/14759276-13-24

16. Ghosh S. Equity in the utilization of healthcare services in India, evidence from National Sample Survey. Int J Health Policy Manag. 2014 Jan; 2(1): 29-38. doi:10.15171/ijhpm.2014.06

17. Anselmi L, Lagarde M, Hanson K. Going beyond horizontal equity, an analysis of health expenditure allocation across geofigureic areas in Mozambique. Soc Sci Med. 2015 Apr;130:216-24. doi:10.1016/j.socscimed.2015.02.012 
18. Dorjdagva J, Batbaatar E, Dorjsuren B, Kauhanen J. Income-related inequalities in health care utilization in Mongolia, 2007/2008-2012. Int J Equity Health. 2015;14(57):1-10. doi:10.1186/s12939-015-0185-8

19. Celik Y. The socio-economic determinants of alternative sources of antenatal care in Turkey. Int J Health Plan Management. 2000;15(3):221-35. doi:10.1002/1099-1751(200007/09)15:3<221::AID-HPM592>3.0.CO;2-A

20. Celik Y, Hotchkiss DR. The socio economic determinants of maternal health care utilization in Turkey. Social Science and Medicine. 2000;50(12):1797-806. doi:10.1016/s0277-9536(99)00418-9

21. Sozmen K, Unal B. Explaining inequalities in health care utilization among Turkish adults, findings from Health Survey 2008. Health Policy. 2016;120(1):100-10. https://doi.org/10.1016/j.healthpol.2015.10.003

22. Erol H, Özdemir A. Türkiye'de sağlik reformlari ve sağlik harcamalarinin değerlendirilmesi [Health reforms and the evaluation of health expenditures in Turkey]. Sosyal Güvenlik Dergisi [J Soc Security]. 2014;4(1):9-34.

23. Fairlie RW. An extension of the Blinder-Oaxaca decomposition technique to logit and probit models. J Econ Soc Meas. 2005;30(4):305-16.

24. Turkey, reforming the health sector for improved access and efficiency. Washington, DC: World Bank; 2003.

25. Health statistics yearbook, 2014. Ankara: Ministry of Health; 2015.

26. OECD health statistics 2015. Country note: How does health spending in Turkey compare?. (http://www.oecd.org/health/ health-systems/Country-Note-TURKEY-OECD-Health-Statistics-2015.pdf, accessed 7 October 2019).

27. Akman M. Türkiye'de birinci basamağın gücü. Türk Aile Hekimliği Dergisi [Turkish J Family Practice]. 2014;18(2):70-8. doi:10.2399/tahd.14.00070

28. Kringos - Pereira Martins D. The importance of measuring and improving the strength of primary care in Europe, Results of an international comparative study. Türk Aile Hekimliği Dergisi [Turkish J Family Practice]. 2013;17(4):165-79.

29. Akdag R. Turkey health transformation programme evaluation report, 2003-2010. Ankara: Ministry of Health; 2010. 